\title{
DEVELOPMENT AND RESEARCH OF ELECTRIC SUPPLY STRUCTURE OF REMOTE POPULATED AREAS BY DIESEL POWER PLANTS
}

\author{
Aleksandr V. Doroshenko a , Nina M. Kosmynina \\ National Research Tomsk Polytechnic University, 634050 Tomsk, Russia
}

Abstract. This paper analyses electric power system of diesel power plants. In this paper proposed the solutions for construction of new diesel power plant and its connection to existing power system.

\section{Introduction}

Russia is the largest country in the world in terms of territories using decentralized power. These include about $70 \%$ of the country area, with a population variously estimated from 10 to 20 million people. These areas are primarily located in the cold or even severe climate, e.g. Siberia, the Far East, and the Far North. The areas with decentralized electricity supply traditionally use installations of small power, i.e. small power plants operating within a certain autonomous power network supplying energy for one or more neighboring communities. The basic fuel for the small-scale power plant in Russia is the diesel, the total amount of which exceeds 47 thousand, and the installed capacity reaches 15 million kilowatts.

Electric power system of diesel power plants (DPP) "South Kuril" provides electricity to urban village Kurilsk South, located on a peninsula Kunashir Island (South Kuril Islands) with a population of approximately 6,500 people.

Block diagram of the energy complex DPP "Southern Kurils," is shown on Figure 1.

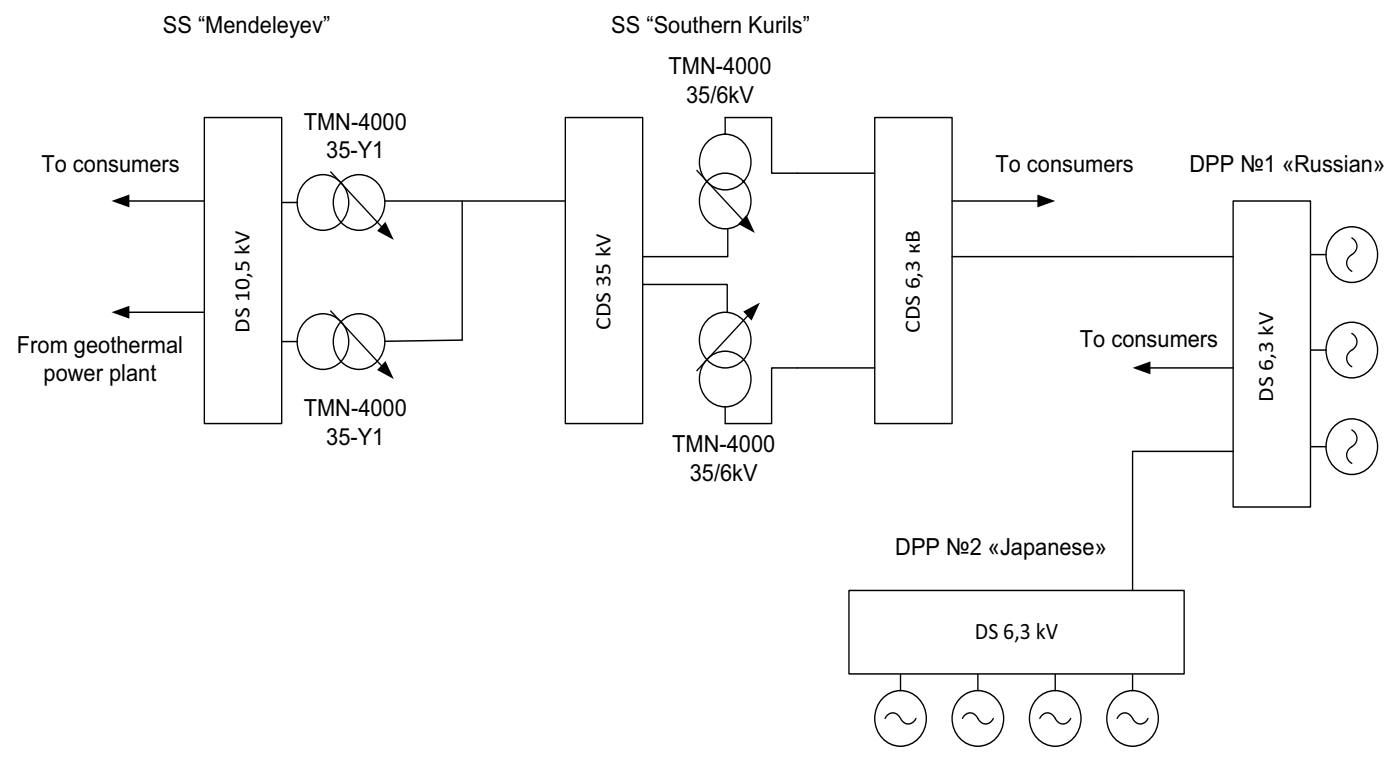

Figure 1. Block diagram of the electric power system "Southern Kuril".

Generating capacity of the energy complex DPP "Southern Kuril" represented by two diesel power plants DPP №1 «Russian" $(2400 \mathrm{~kW})$ and DPP №2 «Japanese" (3200 kW) and two power module geothermal power plant GPP "Mendeleev (3600 kW).

Electric power system also includes two substations (SS): "Southern Kurils" and "Mendeleyev".

At the substation "Southern Kuril" there are two distribution substations (DS) (DS-10.5 kV and DS-35 kV), and two transformers TMN-4000/35/11.

SS " Mendeleyev" also has two distribution substations DS-6.3 kV and DS-35 kV and two transformers TMN-4000/35/6.

SS " Mendeleyev" and SS "Southern Kuril" interconnected by single circuit transmission line formed on a voltage of $35 \mathrm{kV}$ with the wire AS-120.

The total capacity of the load on the DPP in winter can reach a $5000 \mathrm{~kW}$.

${ }^{\mathrm{a} C o r r e s p o n d i n g ~ a u t h o r: ~ a v d 5 @ t p u . r u ~}$ 


\section{Problem statement}

To avoid interruption in the electricity supply to consumers in South Kurilsk by reasons of possible failure of outdated equipment, it is necessary to solve the problem of substitution of the existing power equipment with new power sources electricity.

In this paper we propose the construction of a diesel modular plant. The construction of modular diesel power plant and its connection to the existing power system of South Kurilsk can be accomplished in the shortest possible time. The proposed solution will provide reliable energy power supply and the possibility of decommissioning economically inefficient power equipment.

\section{Results and discussion}

The following major decisions about design of diesel power plant were made.

The most important technical indicators of autonomous diesel power plant which provides decentralized consumers power supply are the quantity and the power of installed power units. These indicators define the reliability of electric power supply and the effectiveness of diesel power plant. In order to perform the choice of the quantity and power of diesel generators it is necessary to solve the optimization problem by choosing the diesel generators of a stationary diesel power plant intended to supply of autonomous consumer. For daily load diagram the following structures of diesel power plant design are possible: eight generators with a capacity of $315 \mathrm{~kW}$, five generators with a capacity of $500 \mathrm{~kW}$, four generators with capacity of $700 \mathrm{~kW}$. Minimum reduced annual cost for a given level of customers' electric power supply reliability is used as the optimization criterion. According to calculation of reduced annual costs it can concluded that the minimum of reduced costs of diesel power plant under consideration corresponds to its structure of the four diesel generators. Each of them has the power of $700 \mathrm{~kW}$.

Summation of diesel-generator power is carried out on the busbar projected unit DS-6.3 kV. The simplest and most reliable electrical circuit on the side of $6-10 \mathrm{kV}$ is one busbar system [1].

Currently voltage switchgear $6 \div 10 \mathrm{kV}$ are available as complete. There are some models of switchgears that possible to install: CRU series K-66, CRU series TEL, CRU "Classics" series D-12P [2]. The last device was taken into account.

The main advantage of roll-out switchgears is fast interchange ability of devices mounted on the trolley, which is especially important for electricity generating and responsible plants [3].

Connecting the generator sets to the buses is provided by vacuum switches input cells generated voltage switchgear. In the switchgear D-12P installed vacuum switches BB / TEL [4]. Switch BB / TEL has the following advantages: high mechanical and switching resource, small size and weight, low energy consumption for control circuits, reasonable price. After calculating shortcircuit currents switches BB / TEL-10-12,5 / 630-U2 were chosen.

The role of the bus and line disconnecting devices operate isolating contacts primary connections plug-in type, fixed part of isolating contacts is installed in the body of the cabinet, and the mobile - on the trolley. Lack of disconnecting devices and use instead of them special sliding contacts plug type can increase the reliability and usability of their cameras engineering service.

Outdoor network $6 \mathrm{kV}$ cable provided power lines routed from generators diesel generator sets of modular type to cells entering the generator voltage switchgear $6,3 \mathrm{kV}$, and two lines routed from the projected $6.3 \mathrm{kV}$ switchgear assembly DPP to $6.3 \mathrm{kV}$ switchgear substation "Southern Kuril" in order to preserve the existing power connections and in hut-content of overload feeders DPP №2 "Japanese".

Block diagram of the energy complex DPP "Southern Kurils," with the projected DPP is shown on Figure 2.

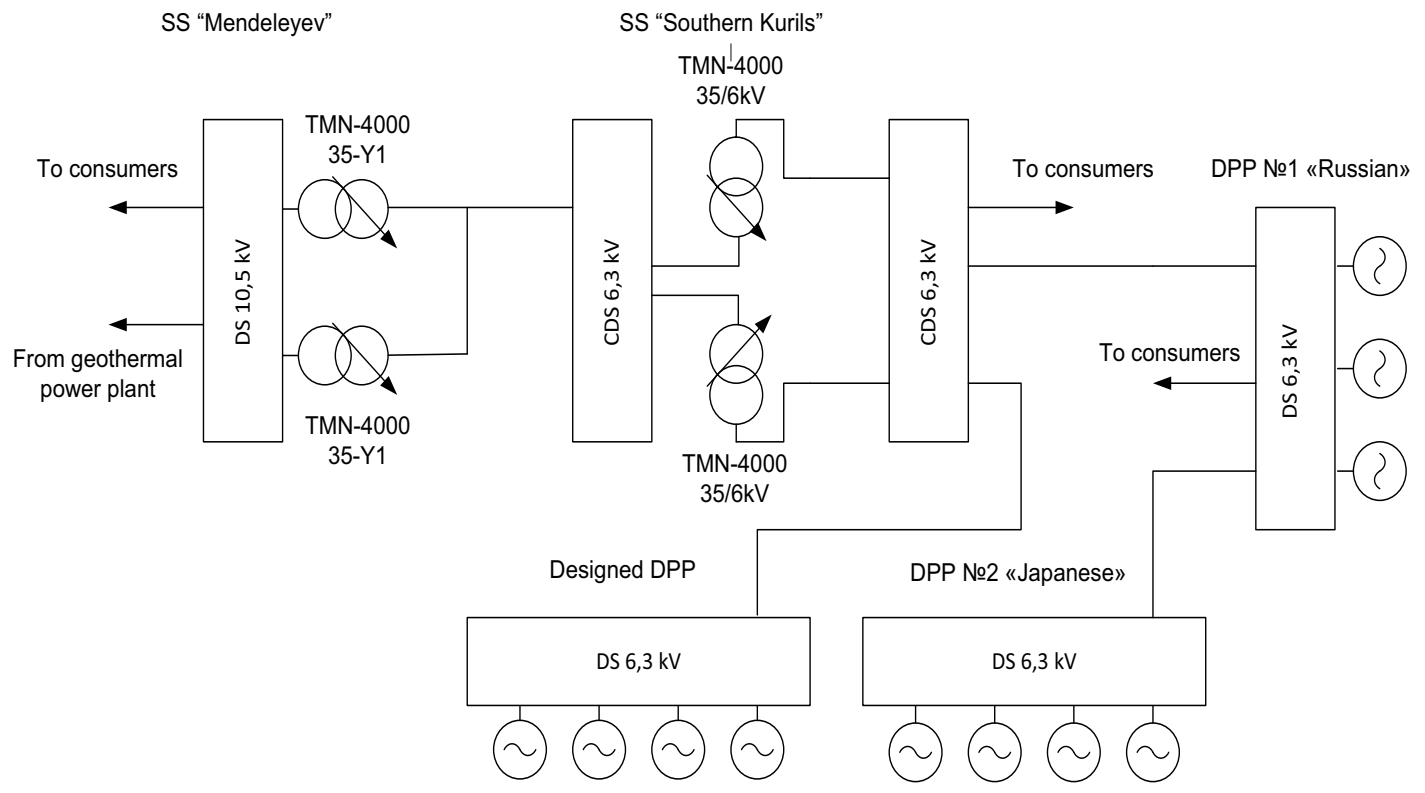

Figure 2. Block diagram of DPP "Southern Kuril" with designed DPP. 


\section{Conclusions}

Adopted solutions provide the possibility of distribution of the sum-total power designed DPP and DPP №2 "Japanese» to the network; the possibility of distribution to the network power from one station if the second is switched off; the possibility of immobilization from the network any of the two half-sets designed DPP, with the possibility of distribution to the network $50 \%$ of rated power plant. This solution allows to provide systematic technical activities service of the station equipment and as a result, improve quality of the maintenance.

\section{References}

1. L.D. Rozhkova, V.S. Kozulin. Electrical equipment stations and substations. Textbook for colleges. 3rd edition. Moscow, Energoatomizdat, 1987.

2. F.F. Grinchuk, S.V .Havronichev. Complete switchgear 6-10 kV. Volgograd, 2006.

3 G.N. Opoleva. Circuits and power supply substations. Moscow Forum Infra-M, 2009.

4. Complete switchgear 6-10 kV "Classics" series D-12P. Manual. 